does not provide sponsors undue influence on choices made in the provision of care.

Competing interests: Dr. Leonard declares no competing financial or personal interests.

Correspondence: Dr. Michael Leonard, Children's Hospital of Eastern Ontario, Division of Pediatric Urology, 401 Smyth Rd, 0ttawa, ON KIH 8Ll; mleonard@cheo.on.ca

\section{Making it hard to rationalize gift exchanges}

\author{
Karen Psooy, MD, FRCSC \\ Winnipeg Children's Hospital, University of Manitoba, Winnipeg, MB
}

Cite as: Can Urol Assoc J 2014;8(1-2):17. http://dx.doi.org/10.5489/cuaj.1925

Published online February 10, 2014.

We all like to see ourselves as honest. As physicians, when we accept a gift for which there may be some ethical implications, our natural tendency is to rationalize the action. Therefore, such opportunities need regulation. In Canada, the Royal College of Physicians and Surgeons of Canada, universities and health authorities have made policies to limit industry-physician interactions that might promote reciprocity. While mandatory public reporting would not disallow the offering and acceptance of gifts, it would make rationalization more onerous. If the funding that physicians currently receive for education, research and honoraria is deemed reasonable by the public, then it should continue irrespective of disclosure. However, that which would not survive such scrutiny should probably cease, law or not.

Competing interests: Dr. Psooy declares no competing financial or personal interests.

Correspondence: Dr. Karen Psooy, Winnipeg Children's Hospital, AE301 - 840 Sherbrook Street, Winnipeg, MB R3A 1S1; kpsooy@hsc.mb.ca

\section{Building a foundation of honesty, integrity and transparency}

\section{J. Curtis Nickel, MD, FRCSC}

Professor of Urology, Queen's University at Kingston, Tier One Canada Research Chair in Urology, Kingston, ON

Cite as: Can Urol Assoc J 2014;8(1-2):17. http://dx.doi.org/10.5489/cuaj.1927 Published online February 10, 2014.

As a physician whose academic career has been enhanced by association with medical related industry, I know the real tangible benefits and understand the dangerous pitfalls of such a relationship. The value of this long-term connection between urology and industry includes financial support for ongoing medical education and teaching within our urology programs and our wider urology community, independent peer reviewed research grants not necessarily linked to any marketed product, involvement in important clinical trials, opportunities to be engaged in early product and drug development and assisting industry to better align their programs to the needs of the urological community and our patients. While I believe that time, effort and expertise require fair compensation, the problem with this relationship lies in real and perceived bias in terms of advocating for specific marketed products and/or pharmaceuticals. The answer to this dilemma is not to cut all ties with the medical industry, but rather base our ongoing relationship on a foundation of honesty, integrity and transparency. One cannot legislate honesty and integrity, but we can insist on transparency full disclosure of all relationships, financial and otherwise, between individual physicians, academic institutions and our industry partners.

Competing interests: Dr. Nickel is was an investigator and consultant for Glaxo-Smith-Kline, Taris Biomedical, Pfizer, Stellar Pharmaceuticals, Watson Pharmaceuticals; a consultant, investigator and speaker for Eli Lilly; a consultant and speaker for Astellas; an investigator for Johnson and Johnson, Aquinox; a consultant for Farr Laboratories, Trillium Therapeutics, Auxillium and Ferring.

Correspondence: Dr. J. Curtis Nickel, Department of Urology, Queens University, Kingston, ON K7L 2V7; jin@queensu.ca 